\section{PO-1000 THE CORRELATION BETWEEN PH AND CALCIUM, NATRIUM, KALIUM IN TREATED PATIENS WITH MODERATE ASTHMA EXACERBATION}

A Brumar, M Neamtu. Pediatric Clinic, "Victor Papilian" Faculty of Medicine ULBS, Sibiu, Romania

\subsection{6/archdischild-2014-307384.1618}

Background Salbutamol induces stimulation of beta2-receptors resulting in hypokalemia. Corticosteroids also induce plasma electrolytes variations.

Aims 1. To identify the relation between pH-Calcium (Ca), pH-Natrium (Na) and $\mathrm{pH}-\mathrm{Kalium}(\mathrm{K})$ following low dose inhaled short-acting beta2-agonists. 2 . To evaluate if concomitant inhaled corticosteroids treatment can modify the relation.

Methods We analysed all children admitted for moderate asthma exacerbation during 6 months period. Inclusion criteria: children between $5-18$ years of age; PEF $>50-75 \%$ of predicted value; serum electrolytes normal ranges. Exclusion criteria: previously treated patients with Salbutamol; Salbutamol hypersensitivity; others asthma exacerbation severity levels. The patients were divided into 2 groups: 1st group comprised those treated with beta2-agonists and 2 nd group is represented by paediatric patients concomitantly treated with beta2-agonists and corticosteroids. Both groups were homogenous regarding age and sex ratio. During hospitalisation, patients received standard low dose of Salbutamol by metered dose inhaler (MDI) and inhaled Fluticasonum propionate using spacer device with mouthpiece. Included patients were assessed for electrolytes serum levels and $\mathrm{pH}$ before treatment and $72 \mathrm{~h}$ after therapy. Data was analysed statistically using the Pearson correlation.

Results Among 269 admitted patients, 164 children fulfilled inclusion criteria. Both groups structure: 85 children in 1st group, 79 in 2 nd group. Authors found for both groups a significant relation between serum $\mathrm{pH}$ and kalium ( $\mathrm{p}$ value 0,010$)$ and no signification between $\mathrm{pH}-\mathrm{Na}$ or $\mathrm{pH}-\mathrm{Ca}$ ( $\mathrm{p}$ value $>0.05$ ).

Conclusions The study demonstrated a single correlation between $\mathrm{pH}-\mathrm{K}$, mainly due to the important kalium variability during Salbutamol treatment.

\section{P0-1001 RELATIONSHIP BETWEEN THE ELECTROLYTES IN TREATED PATIENS WITH MODERATE ASTHMA EXACERBATION}

A Brumar, M Neamtu. Pediatric Clinic, "Victor Papilian" Faculty of Medicine ULBS, Sibiu, Romania

\subsection{6/archdischild-2014-307384.1619}

Background Salbutamol induces stimulation of beta2-receptors resulting in hypokalemia. Corticosteroids also induce plasma electrolytes variations.

Aims 1. To identify the relation kalium, calcium and natrium following low dose inhaled short-acting beta2-agonists. 2. To evaluate if concomitant inhaled corticosteroids treatment can modify the relation.

Methods We analysed all children admitted for moderate asthma exacerbation during 6 months period. Inclusion criteria: children between 5-18 years of age; PEF $>50-75 \%$ of predicted value; serum electrolytes normal ranges. Exclusion criteria: previously treated patients with Salbutamol; Salbutamol hypersensitivity; others asthma exacerbation severity levels. The patients were divided into 2 groups: 1st group comprised those treated with beta2-agonists and 2 nd group is represented by paediatric patients concomitantly treated with beta2-agonists and corticosteroids. Both groups were homogenous regarding age and sex ratio. During hospitalisation, patients received standard low dose of Salbutamol by metered dose inhaler (MDI) and inhaled Fluticasonum propionate using spacer device with mouthpiece. Included patients were assessed for electrolytes serum levels and $\mathrm{pH}$ before treatment and $72 \mathrm{~h}$ after therapy. Data was analysed statistically using the Pearson correlation.

Results Among 269 admitted patients, 164 children fulfilled inclusion criteria. Both groups structure: 85 children in 1 st group, 79 in 2 nd group. Authors found for both groups a significant relation between serum kalium, serum calcium and natrium. (pvalue 0,010). The study didn't confirm a significant variation of serum electrolytes in 2 nd group as compare to 1 st group.

Conclusions Study confirmed significant relationship between the serum electrolytes (kalium-calcium, kalium-natrium) after 72 $\mathrm{h}$ inhaled treatment with beta2-agonists.

\section{PO-1002 THE SIGNIFICANCE SOLUBLE MARKERS OF ACTIVATION AND APOPTOSIS OF IMMUNE CELLS IN CHILDREN WITH ATOPIC BRONCHIAL ASTHMA}

${ }^{1} \mathrm{~V}$ Bulgakova, ${ }^{2}$ B Balabolkin. 'Department of Scientific Research, Scientific Centre of Children Health, Moscow, Russia; ${ }^{2}$ Department of Pulmonology and Allergology, Scientific Centre of Children Health, Moscow, Russia

\subsection{6/archdischild-2014-307384.1620}

Background In the pathogenesis of allergic diseases it is assumed the role of apoptotic mechanism of allergic inflammation and immunosuppression.

Objective To define clinical value of apoptosis markers of immunocompetent cells at children with atopic bronchial asthma (BA). Materials and methods In blood serum of the 96 children in the age from 5 till 16 years (15 healthy and 81 with BA) by enzymeimmunoassay analysis of the use of commercial sets certain level of soluble membrane molecules, which are markers of modulation processes activation and apoptosis of immunocompetent cells: sCD30, sCD40, sCD95 (sApo-1/FAS), soluble FAS ligand (sFASL), ligand TRAIL (Apo2L), enzyme Caspase-1/ICE and protein Annexin V.

Results Authentic differences of concentration of the investigated indicators at children with BA from their referential levels (p).

Conclusion The level estimation soluble markers of activation and apoptosis immune cells can be used as additional diagnostic and prognostic criterion of weight and expressiveness of an atopic bronchial asthma at children.

\section{PO-1003 CHARACTERISTICS OF THE IMMUNE RESPONSE TO INFLUENZA VACCINE IN CHILDREN WITH ALLERGIC DISEASES}

${ }^{1}$ V Bulgakova, ${ }^{2}$ B Balabolkin. ${ }^{1}$ Department of Scientific Research, Scientific Centre of Children Health, Moscow, Russia; ${ }^{2}$ Department of Pulmonology and Allergology, Scientific Centre of Children Health, Moscow, Russia

\subsection{6/archdischild-2014-307384.1621}

Background Patients with chronic diseases, including atopic bronchial asthma (BA), should be vaccinated annually against influenza. Purpose. To determine the impact of vaccination 
against influenza in the state of immune response in children with atopic BA.

Object Studied immune status of 39 children with moderate persistent BA in children from 7 to 14 years, which annually for three years were vaccinated influenza subunit vaccine.

Methods Compared the levels of serum markers of activation of apoptosis and immune cells before and one month after vaccination. Results. After the vaccination was determined by the tendency to increase of level of IFN $\gamma$ and IL12 in the serum. Also demonstrated increased in 1.3 times sCD25 ( $p<0.05)$, in 1.6 times IL8 $(p<0.001)$, reduction in 1.5 times IL4 $(p<0.001)$, in 1,3 times $\operatorname{TNF} \alpha(\mathrm{p}<0.05)$. In vaccinated children was revealed a tendency to increase $\mathrm{sCD} 25$ and the reduction of $\mathrm{sCD} 30$, sCD95 $(\mathrm{p}<0.05)$, with the all of the listed indicators were significantly rejected from the reference levels. Reliable dynamics of the content of eotaxin, soluble ligands markers of apoptosis sFASL, TRAIL (Apo-2L), the enzyme Caspase-1/ICE and protein Annexin V have been identified.

Conclusions The data show a pronounced inflammatory process in children with atopic bronchial asthma. At the same time, the observed dynamics of the studied indicators can be interpreted as evidence of an absence of negative impact of vaccination on the various links of the immune response in children with atopic bronchial asthma, including on the processes of activation and apoptosis.

\section{PO-1004 WITHDRAWN}

\section{PO-1005 CORRELATION BETWEEN LUNG ULTRASOUND AND CHEST X-RAY: ANALYSIS IN A SELECTED CHILDREN COHORT}

C Casini, M Barreto, C Pacchiarotti, L Brasili, MC Paolino, MP Villa. Pediatrics, S Andrea, Roma, Italy

\subsection{6/archdischild-2014-307384.1622}

Introduction Lung ultrasound findings in infants and children are similar to those described in adults.

Despite ultrasound screening avoids the use of ionising radiation, the interest of specialists toward lung ultrasound examinations is still scarce.

Aims To compare lung ultrasounds with chest X-ray imagines for diagnosis of pneumonia and pleural effusion and to evaluate the ultrasound pattern in patients with Mycoplasma Pneumoniae infection.

Materials and methods Forty children (mean age $4.2 \mathrm{yr}, 21$ females), admitted in the paediatric ward for respiratory tract infections, underwent chest X- ray, lung ultrasound examination and serum sample for Mycoplasma Pneumoniae. Presence of ultrasound B-lines was accepted as a signal of interstitial involvement.

Results Chest X-ray and ultrasound examination yielded concordat results for pneumonia and/or pleural effusion in 29/40 $(72,5 \%)$ patients. In addition, ultrasounds detected pleural effusion in 10 patients, not revealed by chest X-ray imagines.

Ultrasound B-lines were found in 5/8 (62.5\%) Mycoplasmapositive in contrast with only $7 / 32(21,8 \%)$ Mycoplasma-negative patients $(\mathrm{p}<0.05)$.

Conclusions Lung ultrasound examination is safe, can be performed repeatedly and complement chest X-ray for assessing pneumonia and pleural effusion in infants and children. An ultrasound pattern with increased B-line could be useful to assess interstitial involvement by Mycoplasma infection.

\section{P0-1006 RECIPIENTS WITH IN UTERO INDUCTION OF TOLERANCE UP-REGULATED MHC CLASS I IN THE ENGRAFTED DONOR SKIN}

${ }^{1} \mathrm{JC}$ Chen, ${ }^{2} \mathrm{ML}$ Kuo. ${ }^{2}$ Department of of Pediatric Surgery, Chang Gung Memorial Hospital, Taoyuan, Taiwan; ${ }^{2}$ Department of Microbiology and Immunology, College of Medicine Chang Gung University, Taoyuan, Taiwan

\subsection{6/archdischild-2014-307384.1623}

Background and aims The alterations in MHC class I expression play a crucial step in immune evasion of cancer or virus-infected cells. This study aimed to examine whether tolerized grafts modified MHC class I expression.

Methods FVB/N mice were rendered tolerant of $\mathrm{C} 57 \mathrm{BL} / 6$ alloantigens by in utero transplantation of $\mathrm{C} 57 \mathrm{BL} / 6$ marrows. Postnatally, engrafted donor skins and leukocytes were examined for their MHC expression by quantitative real-time PCR and flow cytometry.

Results In this murine tolerance model established by in utero marrow transplantation, engrafted donor skins up-regulated their MHC class I related gene transcripts after short-term (1 2 weeks) or long-term (>1 month) engraftment. This biological phenomenon was simultaneously associated with up-regulation of TAP1 gene transcripts, suggesting an important role of TAP1 in the regulation of MHC class I pathway. Notably, the surface MHC class I molecules of $\mathrm{H}-2 \mathrm{~K}^{\mathrm{q}}$ in engrafted donor leukocytes consistently showed over-expression.

Conclusions Induction of allograft tolerance involved biological modifications of donor transplants. The increased expression of MHC class I within engrafted donor skins of tolerant mice might be used as the tolerance biomarkers for identifying a state of graft tolerance, and paved the way to advancing our insights into the mechanisms of allo-tolerance induction.

\section{P0-1007 ASSOCIATION BETWEEN THE CC16 A38G POLYMORPHISM AND CLINICAL PHENOTYPES OF ASTHMA IN MOLDAVIAN CHILDREN}

${ }^{1} \mathrm{O}$ Cirstea, ${ }^{2} \mathrm{~L}$ Vasilos, ${ }^{3} \mathrm{~T}$ Ivashchenko, ${ }^{2} \mathrm{~A}$ Cojocaru, ${ }^{3} \mathrm{M}$ Aseyev, ${ }^{2} \mathrm{D}$ Savoschin. ${ }^{1}$ Pediatrics, State Medical and Pharmaceutical University Nicolae Testemitanu, Chisinau, Moldova; ${ }^{2}$ Scientific Department of Pediatrics, Institute for Maternal and Child Healthcare, Chisinau, Moldova; ${ }^{3}$ Laboratory of Prenatal Diagnostics and Inherited Diseases, Ott's Institute of Obstetrics and Gynecology Russian Academy of Medical Sciences, St. Petersburg, Russia

\subsection{6/archdischild-2014-307384.1624}

Background and aims The protein CC16 is secreted in airways by the nonciliated bronchiolar Clara cells and has an important role in inflammation and immune modulation. Our study aimed to investigate the association of the CC16 A38G polymorphism with asthma severity in Moldavian children.

Methods A case-control study was used to detect the genotypes of $38 \mathrm{~A} / \mathrm{G}$ of CC16 gene of 90 patients with asthma and 90 controls from the Moldavian ethnic group by polymerase chain reaction-restriction fragment length polymorphism. All patients underwent complex clinical and functional examination.

Results No significant differences were observed in the frequencies of polymorphic genotypes in site 38 of CC16 gene between asthmatic children and control subjects $(\mathrm{p}>0.05$, genotype frequency: $\mathrm{AA}+\mathrm{AG}$ : $61.1 \%$ vs. $58.9 \%$ ). The frequency of A allele 